\title{
Twitter Based Digital Social Movement Pattern to Fight COVID-19
}

\section{Mohammad Thoriq Bahri}

Faculty of Law and Political Sciences, University of Szeged, Hungary \& Directorate General of Immigration, Ministry of Law and Human Rights, Republic of Indonesia (email: mohammad.thoriq@kemenkumham.go.id)

\author{
Derajad Sulistyo Widhyharto \\ Department of Sociology, Faculty of Social and Political Sciences, Universitas Gadjah Mada \\ (email: derajad@ugm.ac.id)
}

\begin{abstract}
Twitter has become a tool for people to trigger a social change, like what is happening right now during COVID-19 outbreaks. Most people are using social media platforms to express their perspectives. For the first time, this research aimed to analyze the pattern of a social movement that happened during COVID-19 Outbreaks by analyzing the Twitter dataset contains 23,476 tweets worldwide with the \#COVID19 hashtag which was obtained from 02 March to 09 April 2020. Social Network Analysis tools are used to understand the pattern of movement. This research concluded that if the Government and Mainstream Media Twitter account triggered the conversation in the social media platform, followed by the activists and celebrities who engage in conversation between their followers, an ordinary person spread the point of view of the Government and Mainstream Media across their conversation network. The COVID-19 hashtag successfully engaged 10 protest clusters, which pushed the people to fight against COVID-19 in their countries, mostly targeting the government-related account. The digital social movement pattern is relatively different from the traditional social movement, even it has the same steps, which emerge, coalesce, bureaucratise, and the movement itself, but it takes place in the Digital Public Sphere without any social or political boundaries. The digital social movement forced the government to implement a better policy to fight the COVID-19 Pandemic, including to close the national border to prevent unnecessary effects of International Migration.
\end{abstract}

\section{Keywords:}

COVID-19; digital social movement; twitter; SNA; immigration

\section{Introduction}

The inventions of the Internet transform the social structure and interaction pattern of society. The transformed society, known as "Information Society" (Petrič, 2006). In the era of the Information Society, people are talking on the Internet, and that conversation can trigger a social movement (Navarria, 2019).

The social movement itself can be defined as a movement organized, involving informal social entities that engage in extra-institutional conflict towards a common goal (Porta \& Diani, 2020). In social movement theory, the common goal between the involved entities becomes the most important aspect of how the digital social movement can be triggered.

In the era of the information society, Twitter is one of the social media platforms, which provides real-time updates about what happen in the world, most simply and efficiently, better than any other social network platform in terms of spreading information across different conversation networks resulted in the public engagement (Papacharissi \& de Fatima Oliveira, 2012). With the use of the hashtag, Twitter is conceptualized as the 
big data-producing platform. The big data produced by the Twitter platform can help the researcher to understand the facts by analyzing the conversation clusters, to understand relationships between the related actors, and discussion issues (Larson et al., 2019).

The main challenge is not easy to understand the interactions and the social movement potential which happened on the Twitter platform. Because, to understand the conversation, it requires big data analysis (Barbier et al., 2013). Big data analysis changes how social research is conducted, without survey, without margin of error and the results can be borderless, from any segment of society (Rob, K., 2014).

Social Network Analysis (SNA) was developed as the new method to understand thousands of the tweets which used the COVID-19 related hashtag, using the big data analysis to understand the conversation which happened in the Twitter platform. The SNA analysis is becoming very important to understand the directions of the digital social movement which is engaged by a wide part of society.

The digital Social Movement by using hashtags is known as the most effective way to create borderless movement, from the grassroots to the elites communities. On the other hand, different from the traditional social movement only happening in one layer of society, the digital movement in the Twitter platform spread across social dimensions, structure, and overlay existing power relations in movements (Polletta \& Jasper, 2001). Furthermore, the COVID-19 pandemic is creating a digital social movement in the Twitter platform, pushing the government to make better policies to fight the COVID-19 pandemic, with more than 628 million tweets recorded using the COVID-19 hashtag as per May, $8^{\text {th }} 2020$ (Binder, 2020).

This research aimed to understand the pattern of the digital social movements during the outbreaks of COVID-19, and its side effects on the related policy, including the border closing policy which affected International Migration by analyzing 26988 related hashtags obtained from the Twitter database from 02 March to 07 April 2020. The pattern of the movement will be identified, and the impact of that digital social movement on the government actions and policy against the COVID-19 pandemic will be explained with the timeline analysis. The findings can help to understand how the conversation on social media platforms can trigger a social movement during the COVID-19 Pandemic.

\section{Literature Review}

The social movement is not part of the political or initiated by the political party, which has political access, power, and is not formally organized, it's defined as something in between the political, and well-organized movement (Porta \& Diani, 2020). The identified characteristics of social movements are "the member has collective relation to fights against a clear opponent; also, they have a collective identity". A social movement can be concluded as organized informal social entities that have common institutional conflict, with the same interest against a clear opponent, and the movement itself oriented in one collective goal. The social movement goal itself can be aimed at a specific government policy or even a cultural and social change.

There are some of the stages to start a social movement; those steps are defined as Emergence, Coalescence, Bureaucratization, and Decline (Porta \& Diani, 2020). The actors of the social movement itself can be identified as three main key actors. First, the victim of a policy. Their activities are circulating the information and organizing the members who come from the people who are directly impacted by the government policy (Yates, 2015).

The second key actors of a social movement are the elites who join the movement during the second phase. When policy change is one of the 
main goals of social movements, it will create an opposition group involving elites. such as political leaders, social activists, journalists, and even government officials (Mattoni \& Treré, 2014).

The third key actors are common people who are not core actors or elite actors. These actors are uncommon in the traditional social movement, but they are becoming key actors in the digital social movement era (Hodges et al., 2016). The ordinary people, who became active in social media, play significant roles, from spreading the information to mobilizing the audience's attention, developing and enlarging the movement, and keeping the digital social movement active (Isa \& Himelboim, 2018).

On the other hand, the digital social movement has the relatively same pattern, but with different characteristics. The development of the new digital ecosystem and increasing penetration of the internet makes it possible for the oppositional public space (OPS), with the borderless actors. In the digital social movement, the common goal is making the relationship between the actors who come from the influencer, government, and ordinary people becoming blurry and borderless (SierraCaballero, 2018). The use of the hashtag has revolutionized the way we can trigger a social movement.

From the first-time hashtag invention, it's already been used for political activism. In 2005, the "Barcamp" hashtag was used by Messina to talk about the issues which happen in the United States. The hashtag itself is already used for creating together voices, which cannot be created by the traditional media system such as television and radio (Bernard, 2019).

The digital age social movement is a relatively new phenomenon. The movement must be identified by knowing how it spread, how the pattern and the main goal, by understanding the conversation starter, influencer, active engager, Network builder, and Information bridge, after identification of the pattern, the timeline analysis must be conducted to understand the impact of the digital social movement to the government policy or decision (Barbier et al., 2013). That perspective will be used for analyzing the sample as linear with the aim of this research, to analyze the pattern of the digital social movement and the impact on the government policy and decision by using the timeline analysis. The analysis of the Twitter hashtag is important, because Twitter is becoming the main social media service, a simple way to spread ideas only with 140 characters, and have a borderless reach.

\section{Methods}

The qualitative method with the Social Network Analysis (SNA) will be used as the research framework. The main pattern of interaction will be captured, and the timeline analysis of government policy and the decision will be conducted to understand the impact of the COVID19 related hashtags on the Twitter platform. The data analysis will be conducted by using the big data analysis with NodeXl, RStudio, and Gephi mapping software. The data extraction is conducted with data mining, which is the process of extracting data and patterns from large datasets (Rob, K., 2014).

It is premised on the notion that all massive datasets hold meaningful information that is non-random, valid, novel, useful, and ultimately understandable (Bode et al., 2015). The selection of methods varies between the type of data (structured, unstructured, or semi structured) and the purpose of the analysis.

The uses of SNA represent a distinctive set of methodologies to map, measure, analyze social relationships between people, teams, and organizations (Park et al., 2015). The SNA analysis enables exploration of the patterns and types of relationships between actors, where these actors (individuals, groups, or organizations) are represented in a network map by structural nodes, and relationships 
Table 1.

Data Mining tasks and techniques

\begin{tabular}{|c|c|c|}
\hline Data Mining Task & Description & Techniques \\
\hline Segmentation or Clustering & $\begin{array}{l}\text { Clustering the groups that describes the } \\
\text { data }\end{array}$ & - Cluster Analysis \\
\hline Classification & Add the labels to the datasets & $\begin{array}{l}\text { - } \text { Bayesian classification } \\
\text { - } \text { Decision tree induction } \\
\text { - } \text { Artificial Neural Networks } \\
\text { Support Vector Machine }\end{array}$ \\
\hline Association & $\begin{array}{l}\text { Analyzing the relation between the users, } \\
\text { and conversation clusters }\end{array}$ & $\begin{array}{l}\text { - Association rules } \\
\text { - Beyesian networks }\end{array}$ \\
\hline Deviations & $\begin{array}{l}\text { Wrapping up the items, to understand the } \\
\text { information spread }\end{array}$ & $\begin{array}{l}\text { - } \text { Cluster analysis } \\
\text { - Outlier detection } \\
\text { - Evolution analysis }\end{array}$ \\
\hline Trends & $\begin{array}{l}\text { Lines and curves summarizing the } \\
\text { database, often over time }\end{array}$ & $\begin{array}{l}\text { - Regression } \\
\text { - Sequence Pattern extraction }\end{array}$ \\
\hline Generalisations & Compact descriptions of the data & $\begin{array}{l}\text { - Summary-rules } \\
\text { - Attribute-orientated induction }\end{array}$ \\
\hline
\end{tabular}

Source: Kitchin, Rob (2014;72)

(ties or links) between these nodes. SNA allows for the analysis of the role of users in a conversation network, it can also characterize and map network relationships, as well as analyze the structure of a system (Larson et al., 2019). SNA provides a theoretical approach to explore the interaction of actors in a system and a framework to test theories around collective behavior and social interaction (Borgatti et al., 1992).

This research using the big data from the Twitter social media platform, dated between 02 March until 09 April 2020, which was chosen because of several reasons. First, On March 2, 2020, WHO announced the new spread of the coronavirus outside China, mostly coming from the most active Twitter-user countries (Indonesia, Senegal, Portugal, Andora, Latvia, Jordan, Morocco, Saudi Arabia, and Tunisia). Second, on March 2, 2020, the United States started committing \$37 million, which was taken from the Emergency Reserve Fund for Contagious Infectious Diseases in the U.S, the US step creating a big impact in the social media information spread. Third, starting from March 2, 2020, the Twitter hashtags related to COVID-19 increased more than nine times than before, with total tweets reaching about 628 Million tweets by May 8, 2020 (Binder, 2020).

After the data is extracted with the NodeXL Software, to evaluate the text of tweets and sentiments in those specific tweets, the analysis tools RStudio software Version. 4.0 with the Snowball, Rstem, TwitteR, TM, NLP, Sentiment Analysis, and Sentiment Packages were used. After that, the interactive map and actors were identified using the Gephi Mapping Software, version 0.9.2. To understand big databased data from Twitter, RStudio programming with Python Language Programming was employed.

Finally, relationships can also be weighted or valued, and this can be used to assess the strength or frequency of informationsharing in a network. By using the method, the study aimed to understand the pattern of social movement which happened during the COVID-19 pandemic.

\section{Data}

The dataset used in this research consists of 23,476 tweets worldwide, obtained from 02 March 2020 to 07 April 2020. The dataset only includes the tweets which contain the 
COVID-19 hashtag. The \#COVID-19 hashtags are appearing as the first hashtag, also this research employs the other hashtags related to the primary hashtag, such as \#fightCOVID-19, \#coronavirusoutbreak, \#stayathome, \#\#lockdown \#dirumahaja \#quarantine \#d \#socialdistancing, those hashtags are still related to the COVID-19 outbreak information. There is an edge for each "replies-to" relationship in a tweet, an edge for each "mention" relationship in a tweet, and a self-loop edge for each tweet that is not a "replies-to" or "mention".

\section{Tools}

The analysis tools, NodeXL software provides three of the clustering algorithms. The first clustering algorithm is the Stanford Network Analysis Platform (SNAP) library, which calculating the network metrics from an analyzed graph (Marc Smith, 2011), the second algorithm is the Wakita-and-Tsurumi algorithm, and the third algorithm, Girvan-Newman algorithm, and the last is Clauset-NewmanMoore algorithm.

This research will be using the ClausetNewman-Moore algorithm to understand connected vertices and spread it into the different groups. Then, the results will be grouped into several databases to analyze the conversation starter, influencer, active engager, Network builder, and Information Bridge.

\section{Results}

Relation between those actors will be identified by conducting a structural analysis on the conversation network by mapping the connection between involved actors by using several indicators, as described in Table 2.

The analysis will focus on the identification and classification of conversation starter, influencer, active engager, Network builder, and Information bridge by using the indicators which were used in the Node XL tools which described before. Explained in Table 2.

The analysis begins with understanding the items which contain a formatted summary of the content analysis showing the most frequently mentioned URLs, hashtags, words, word pairs, and users in each group and the network as a whole. The tweets data in Table 4.

The most active user which uses COVID-19 hashtag to spread their information will be measured by the value of the Betweenness Centrality, which can be explained as how important a node is to the shortest paths through the network. Those users mentioned in the table below have control over the information passing between other users in the networks, in other words, the users above have a big impact in influencing the spread of information in the network. Those users can be shown in Table 5 .

Table 2.

\section{SNA Connection Measures Description}

\begin{tabular}{|c|c|}
\hline Measure & Description \\
\hline Centralization & $\begin{array}{l}\text { The centralization measures the degree to which network links are focused on one or a few } \\
\text { nodes in the network. Networks can be centralized because there is a high standard deviation } \\
\text { of centrality scores. }\end{array}$ \\
\hline Core-Periphery & $\begin{array}{l}\text { The network structures which explained the densely connected group of nodes and others who } \\
\text { are more loosely connected. }\end{array}$ \\
\hline Density & Show the links which are connected per conversation node. \\
\hline Degree centrality & $\begin{array}{l}\text { Degree centrality examines the number of the conversation links which are connected to a person } \\
\text { (in-degree) and from a person (out-degree) in a conversation cluster. }\end{array}$ \\
\hline $\begin{array}{l}\text { Betweenness } \\
\text { centrality }\end{array}$ & $\begin{array}{l}\text { Indicates the shortest path which connects users in the network. It indicates the degree to } \\
\text { understand a strategic position of a user in a conversation network. }\end{array}$ \\
\hline
\end{tabular}

Source: (Brunker et al., 2020) 
Table 3.

SNA Analysis User Classifications

\begin{tabular}{|c|c|c|}
\hline Classification & Description & Graph Description \\
\hline Conversation Starter & $\begin{array}{l}\text { A conversation starter is a user in a network with } \\
\text { numerous "in-degree" links and a few or none "out- } \\
\text { degree" links. Conversation starter is the one, who is } \\
\text { responsible for starting the original topic and flow of } \\
\text { information in the network. }\end{array}$ & \\
\hline Influencer & $\begin{array}{l}\text { An influencer is an opinion leader in the network. } \\
\text { Influencers in a network have plentiful "indegree" } \\
\text { links and few "out-degree" links. Influencers do } \\
\text { influence opinion of other users in the network by } \\
\text { creating frequent tweets that are retweeted by other } \\
\text { users. }\end{array}$ & \\
\hline Active Engager & $\begin{array}{l}\text { An active user in an online discussion network } \\
\text { with many "out-degree" and a few or none "in- } \\
\text { degree" links. Active engagers are eager to distribute } \\
\text { information and make connections in online discussion } \\
\text { networks. }\end{array}$ & \\
\hline Network Builder & $\begin{array}{l}\text { Despite having a few "out-degree" and a few or none } \\
\text { "in-degree" links in online discussion networks, } \\
\text { network builder plays an important role in the } \\
\text { network. Main role of a network builder is connecting } \\
\text { two or more influencers in the network. }\end{array}$ & \\
\hline Information Bridge & $\begin{array}{l}\text { An information bridge is a user in an online discussion } \\
\text { network with a few "in-degree" and "outdegree" } \\
\text { links. Information bridge's role is to assist influencers } \\
\text { and active engagement in the network to connect with } \\
\text { other users. }\end{array}$ & \\
\hline
\end{tabular}

Source : Adalat E Niazi, 2017

Table 4.

Details of the analysed tweet

\begin{tabular}{ll}
\hline Items & Number \\
\hline Retweet & 11336 \\
Tweet & 6203 \\
Mentions In Retweet & 6168 \\
Replies to & 1256 \\
Mentions & 4316 \\
\hline
\end{tabular}

Source: Data Analysis.
The massive interaction using COVID-19 hashtags created a new movement. Which involved a lot of actors from different backgrounds. The Twitter users' backgrounds involved in the COVID-19 hashtag can be divided into journalists, Private Person, Celebrity, Activist, Politician, Social Bot, NGO, International Organization, and Company (Brunker et al., 2020). 
Table 5.

Most Active Users Based on the Value of Betweenness Centrality.

\begin{tabular}{ll}
\hline Top 10 Users & Value \\
\hline realdonaldtrump & 37552839.26 \\
who & 31682360.13 \\
hlgatell & 21794311.18 \\
proceso & 18058752.18 \\
drtedros & 12581839.34 \\
theeconomist & 12445448.53 \\
sethabramson & 11112446.7 \\
jairbolsonaro & 10635786.02 \\
borisjohnson & 10363165.38 \\
apdijvbp & 10188684.86 \\
\hline
\end{tabular}

Source: Data Analysis.

The actor's identification of the profile's backgrounds is conducted by manually analysing the dataset. The resume of the actor's background who involved in the COVID-19 hashtag conversation network divided in Table 6.

This research will identify the conversation starter, influencer, active engagers, networks builder, and Information Bridge using the Clause-Newman-Moore algorithm. The crucial point to understand the digital age movement pattern is to know how the digital social movements are paired and bridging between actors (Poell \& Dijck, 2017). The connection between user measurements based on the parameters in Table 7.

Based on the data above, the identification for the key actors which involved in the COVID-19 related hashtag in the Twitter platform conversation network can be explained as follows:

\section{1) Conversation Starter}

First, the conversation starter was identified using the statistical analysis of edge weight, which showed the network ranking of the top connected Twitter users between others (Smith et al., 2014). Indicated with the high value of edge weight, high value on the "indegree" links and only a few the "out-degree" links (Adalat \& Niazi, 2017). That means the posts from this users are tweeted, replied, and retweeted by most of the accounts who using COVID-19 hashtag, the conversation started in Table 8.

The conversation starter users who identified based on the data analysis, are trying to create a conversation cluster, and building

Figure 2.

COVID-19 Related hashtags Tweets Increasing Trends

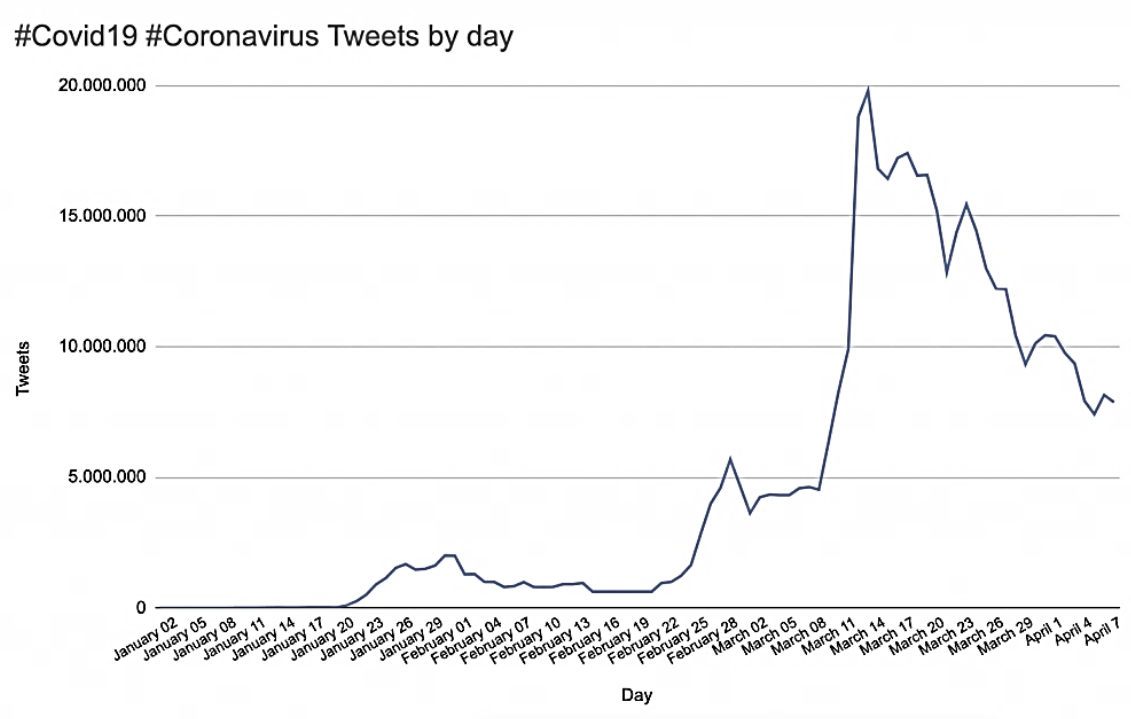

Source: (Binder, 2020) 
Table 6.

Actors Background in the Conversation

\begin{tabular}{lll}
\hline Roles & Percentage & Example \\
\hline Journalist & $6.5 \%$ & Private Account of Journalist \\
Private Person & $25.5 \%$ & Ordinary Citizen \\
Celebrity & $4 \%$ & Public Figures \\
Media & $13 \%$ & Mainstream Media \\
Activist & $3.5 \%$ & Social Activist \\
Politician & $4.5 \%$ & Party Member \\
Social Bot & $1.5 \%$ & Unidentified Account \\
NGO & $1.5 \%$ & Non-Government Org \\
International Organisation & $20.5 \%$ & The Member of the UN Organisation \\
Company & $0.5 \%$ & Private Company \\
Government & $18.5 \%$ & Government Official Account \\
\hline
\end{tabular}

Source: Data Analysis.

Table 7.

Interpretations of Measures

\begin{tabular}{ll}
\hline Centrality Measure & Interpretations \\
\hline Degree & How many people can this person reach directly? \\
Betweenness & How likely is this person to be the most direct route between two \\
Closeness & people in the network? \\
Eigenvector & How fast can this person reach everyone in the Network? \\
\hline
\end{tabular}

Source: (Pond E Lewis, 2019)

Figure 3.

Big Pattern of the COVID-19 Hashtags in the Worldwide Twitter Interactions Between 02 March - 09 April 2020

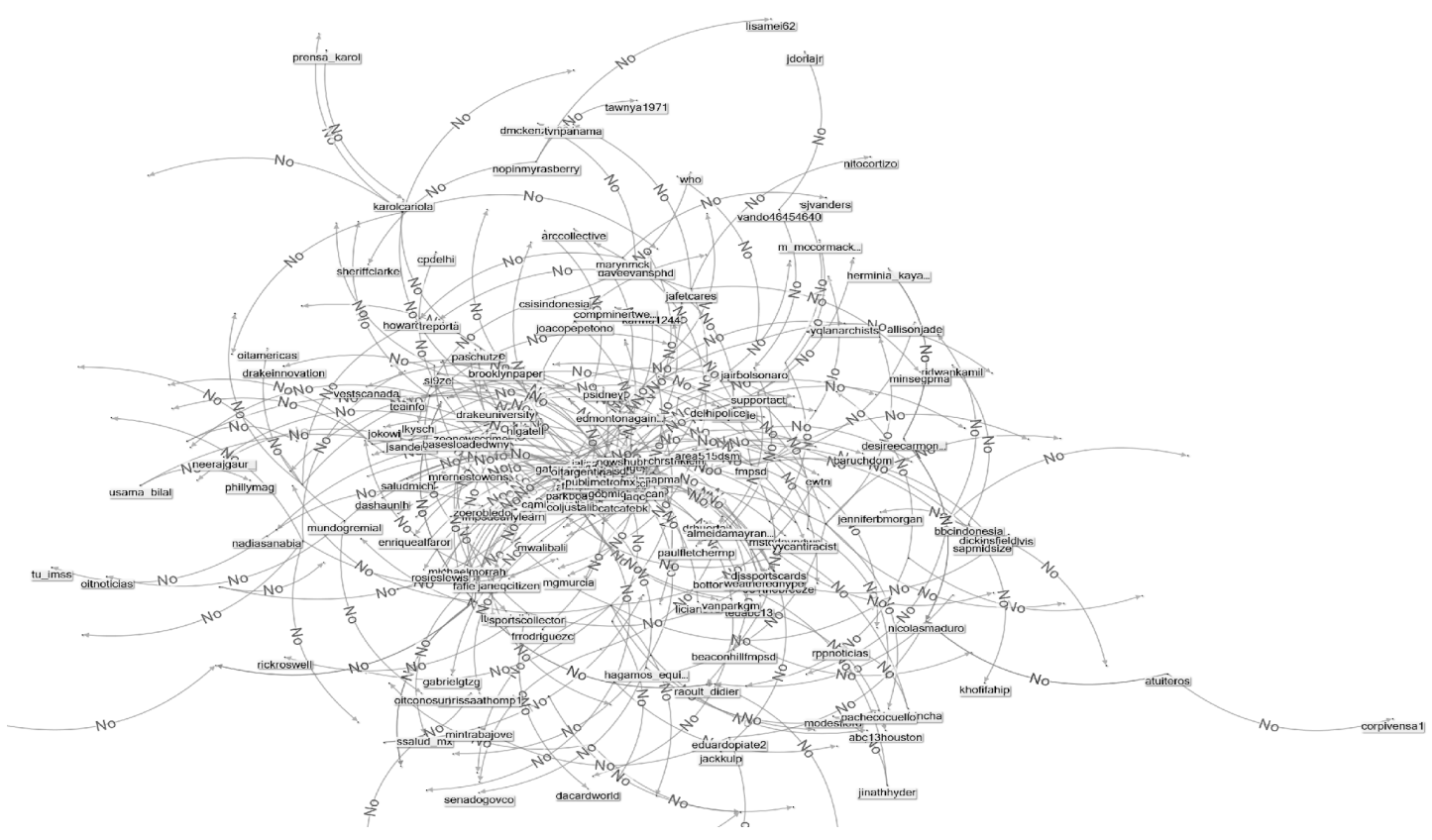

Source: Data Analysis 
Table 8.

The Conversation Starter in the COVID-19 Hashtags

\begin{tabular}{lcl}
\hline Username & Edge Weight Value & Profiles \\
\hline Narendra Modhi & 8 & Celebrity \\
Now This News & 7 & Media \\
Vallejo_Ricky & 9 & Celebrity \\
Gober_cotopaxi & 11 & Celebrity \\
Elfinanciero_mx & 7 & Media \\
Mippzivla News & 11 & Media \\
nhannahjones & 9 & Celebrity \\
Telesur TV Intl. & 7 & Celebrity \\
Mitchellvi & 15 & Celebrity \\
Vtvcanal 8 & 7 & Media \\
ABC Australia & 7 & Media \\
GMA News & 8 & Media \\
Reforma & 7 & Media \\
Detikcom & 7 & Media \\
Amaya071992 & 29 & Activist \\
\hline
\end{tabular}

Source: Data Analysis the public concern regarding issues. The digital social movement can be triggered if a population has a same goals (Porta \& Diani, 2020), and it will start the emergence steps, which is the first steps to form a traditional social movement, the conversation starter, which dominated by the mainstream media creating a common goal, which making the relation between the actors (media and another users) becoming blurry and borderless (Sierra-Caballero, 2018).

\section{2) The Influencer}

Second, the influencer, who created opinions for the users in the conversation network by making frequent tweets, then the tweets are retweeted by other users. The influencer will be identified by using the

Table 9.

The Conversation Influencer

\begin{tabular}{|c|c|c|c|}
\hline User & Graph Analysis & Betweenness Centrality Value & Out Degree \\
\hline Donald. J Trump & & 37552839.262 & 292 \\
\hline Hugo Lopez-Gatell & & 21794311.181 & 467 \\
\hline Jair M. Bolsonaro & & 10635786.022 & 309 \\
\hline Narendra Modi & & 6546600.290 & 160 \\
\hline Scott Jensen & & 2993125.261 & 159 \\
\hline Paul Sperry & & 3992918.734 & 159 \\
\hline
\end{tabular}




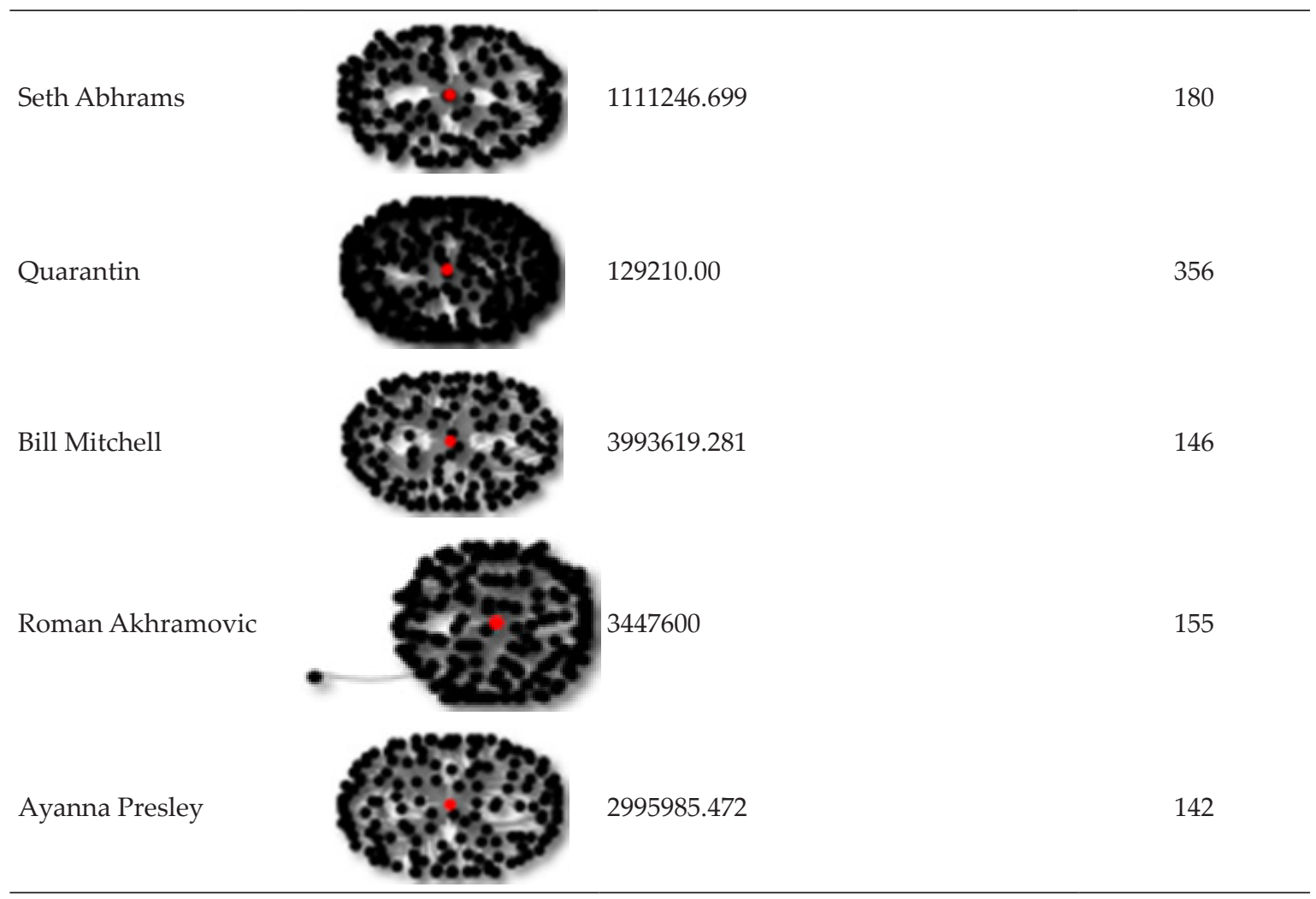

Source: Data Analysis

value of Betweenness Centrality, which shows how likely is this person to be the most direct route between two people in the network. In short, this user has the ability to spread the information to another user in more than one conversation cluster. The identified influencer accounts can be shown in Table 9 .

The Influencer is dominated by government and activist related accounts, which make a selection from the main information which came from the conversation starter, related with their interest. The interest will spread between their followers, and create many of the conversation clusters, with the different common goals. In the traditional social movement, influencer is trying to do Coalescence, which can be defined if the discussions and some perspectives started to be sounded (Flesher Fominaya, 2010).

\section{3) Active Engagers}

Third, the Active Engagers, who spread information massively to their followers, and that information is retweeted by their followers. Indicated by the user who has many "outdegree" and a few or none "in-degree" links. Active engager responsible for the distribution of the information and making connections between another user in a conversation network. Active Engager can be shown in Table 10.

The role of active engager in the digital social movement is building thebureaucratization, which also known as "formalization"(Porta \& Diani, 2020) of the movement, means the actors will becoming organized and there are job specialization between actor to create a success social movement, related to the COVID-19 policy. The active engagement is to keep the conversation cluster alive, and discuss the movement between the members.

\section{4) Network Builder}

Fourth is the Network Builder. The network builder can be identified by the users who have a few "out-degree" and a few or 
Table 10.

Active Engager in the Conversation

\begin{tabular}{|c|c|c|c|}
\hline Username & Graph Analysis & $\begin{array}{c}\text { Betweenness } \\
\text { Centrality Value }\end{array}$ & $\begin{array}{c}\text { Out } \\
\text { Degree }\end{array}$ \\
\hline Naredra Modhi & & 1125.0 & 47 \\
\hline M.G & & 1125.0 & 46 \\
\hline Wgar News Australia & & 930.00 & 45 \\
\hline Orazio Aguerre & & 579118.547 & 47 \\
\hline Ces-Gar Art & & 579118.547 & 43 \\
\hline Old School Fool & & 686.00 & 42 \\
\hline Lady Pooh & & 734.136 & 44 \\
\hline Avenger_2015 & & 471237 & 45 \\
\hline Mortiaty Is Back & & 471237 & 50 \\
\hline KodiakSpall & & 1382198 & 49 \\
\hline
\end{tabular}

Source: Data Analysis 
none "in-degree" links in the online discussion network. The network builder plays an important role in the network. The main role of the network builder is to connect two or more influencers in the network. The analysis of COVID-19 hashtag top 10 Network Builder can be identified as follows:

Table 11.

The Network Builder in the COVID 19 Hashtag Conversation

\begin{tabular}{lcc}
\hline User & In-Degree & Out Degree \\
\hline Chotta_Beem & 0 & 0 \\
Momota & 0 & 0 \\
Monpablo & 0 & 0 \\
Keily Seven Luna & 0 & 0 \\
Liars and Clown & 0 & 0 \\
Aurea Celica & 0 & 0 \\
Leioka & 0 & 0 \\
Siddharta & 0 & 0 \\
Bolortuya Uuganbaya & 0 & 0 \\
\hline
\end{tabular}

Source: Data Analysis

The users above are connecting between conversation clusters in the network, which contains COVID-19 hashtag. The 0 value of the In-degree and Out-degree shows in the Table. Those users are not creating any tweets in their own network or followers, but the role of the Network Builder users is to retweet the tweets from one of the influencers to the other influencer followers, then it will create a new conversation cluster. The role of Network Builder is very important to cross the information between the influencer, then the influencer will control how that information will spread around their network.

\section{5) Information Bridge}

The last step to understanding the digital social movement pattern is to identify the Information Bridge. Information Bridge An information bridge is a user in an online discussion network with a few "in-degree" and "outdegree" links. The information bridge role is to assist influencers and actively engage in the network to connect with other users (Smith et al, 2014).

The analysis results show if there is no information bridge in the COVID-19 hashtags between 07 March to 09 April 2020 In social movement perspectives, the movement already reached the declined steps, which are the last steps of the social movement. The declined steps can be divided into 4 (four) ways, which are Repression, Cooptation, Success and Failure (Porta \& Diani, 2020). The declined steps explained in the discussion steps, when the government starts to adapt the COVID-19 related policy, to minimize the victims of COVID-19.

\section{Interaction Map}

After analyzing all of the conversation related parameters in the COVID-19 Conversation network, the conversation structural analysis will be conducted using the Interaction map (Fig.3) by resuming all of the analyzed data above. The graph's vertices in the COVID-19 Network conversation were grouped by cluster using the Clause-NewmanMoore cluster algorithm which was provided in the Node XL software. The graph analysis was conducted using the Harel-Koren Fast Multiscale layout algorithm. Every conversation between users is shown by using an arrow which illustrates the connection between users in conversation. The figures illustrate the social structure of an digital interaction of the digital social movement which identified in the Twitter platform which used COVID-19 hashtag as shown in Figure 3.

Also, every tweet reply from the users in the conversation is represented as an arrow line with the direction of reply. Size of every dot represents the inward connections between each user. The thickness line arrow represents the number of replies between users in the conversation. The pattern shows the fact that the Government organization is always becoming the object of social movement (Welser 
Figure. 3.

Illustration graphs of the Twitter conversation network in the COVID-19 hashtag represent each user involved in the discussions as a dot.

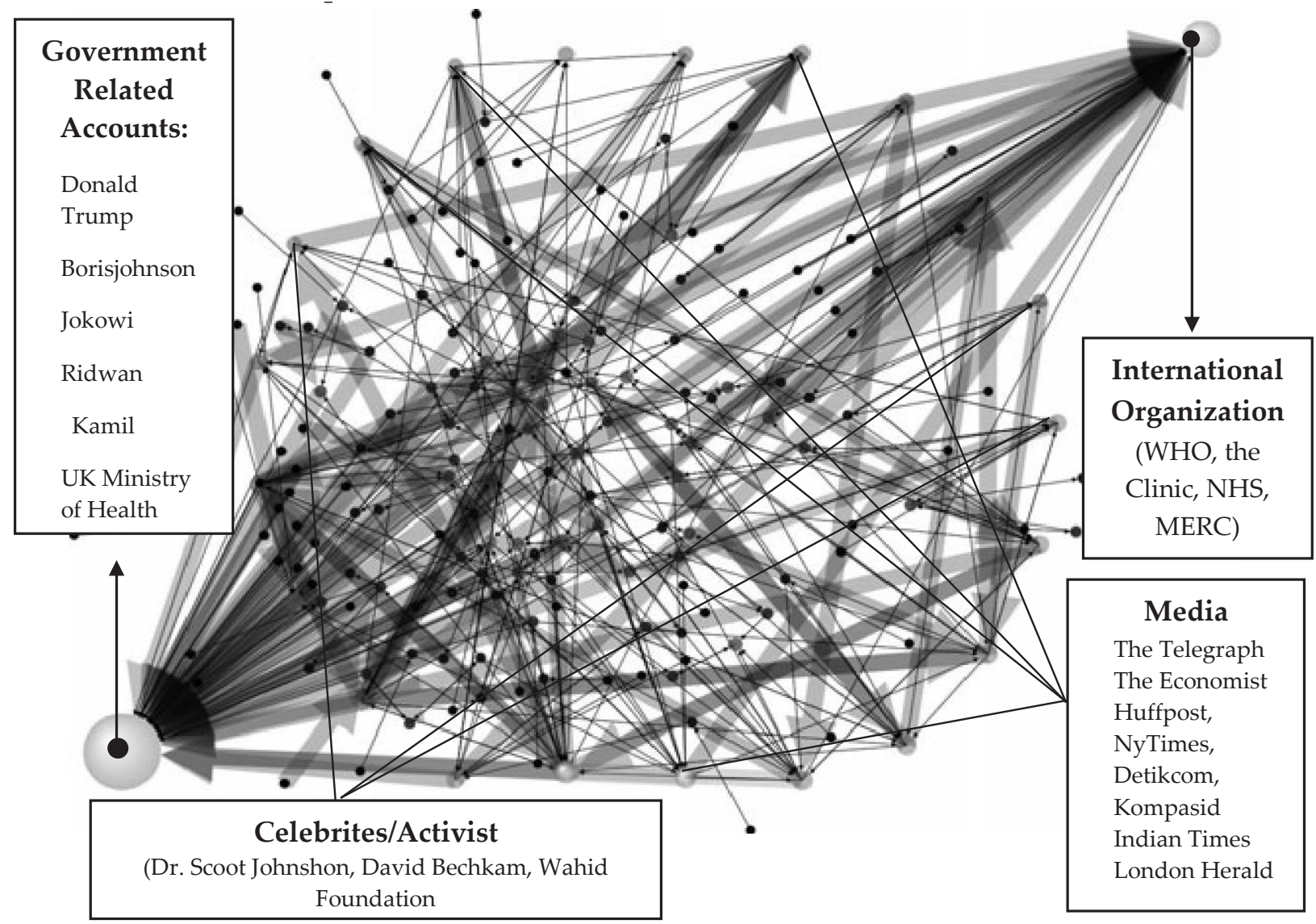

Source : Data Analysis

et al., 2007). As conclusion, the figure illustrate and highlight the presence of two key accounts cluster, contains the Government related users, and the International Organization users located in the two opposite corners, who pushed by the other users, consists of Media, Celebrity/Activist and Ordinary people related to the policy in order to against COVID-19 pandemic.

\section{Discussion}

The research found a big pattern change between the traditional social movement and the digital social movement which happened in the Digital era. The traditional social movement is more concrete, divided into opposite parties, have the same goal and mostly happen in a specified social structure against different social class actors. Social movements are created because the collective is unsatisfied on a certain condition, have enough resources, and have the same identity (Dewantara \& Widhyharto, 2016; Polletta \& Jasper, 2001).

On the other hand, digital social movement can happen because of lowering individual cost for participation in a social movement, increasing general access to specific information, fostering connectivity between users and creating a space for users to publish their own content (Felix et al., 2020). Booming of the social media users creating new concepts which did not exist before, the Public Sphere. The digital public sphere becoming a new public space to discuss issues which happen 
around the social media users, the cross social structure, borderless and multi actors' conversation becoming common (Dewantara \& Widhyharto, 2016). The public sphere is created by the digital native, which is explained as the society, dominated by the young generation who use social media for getting information and discussing specific issues between them (Pond \& Lewis, 2019). Based on the data analysis, some of the findings will be discussed as follows.

The first findings is about how Twitter changed the form of social movement, especially by the use of the COVID-19 hashtag. Twitter, already drastically influencing the forms of the social movements and protests in modern society. Twitter as a social media platform is already creating new insights of diffusion, because of its ability to spread information and ideas directly, without the geographical boundaries. The Twitter users behavior is also breaking the early diffusion theory principles, that believed, to diffuse the ideas rapidly the direct contact between adopters or actors must happen intensively ((Wolfsfeld et al., 2013). This is also validated by the research findings, if the COVID-19 hashtag creates a digital social movement to push government policy, in a relatively short time.

The second findings, also have the supporting argument about the new public sphere which happens on Twitter. The first research findings is that the pattern of the social movement consists of cross social structure, from the Journalist, Private Persons, Celebrity, Media, Activist, Politician, NonGovernment Organization(NGO), International Organization and Government related accounts. The findings are the characteristics of the digital social movement, cross social structural movement with the same goal.

In a digital social movement using social media as tools, grassroots and traditional social actors act as important mediators in a new public sphere, however, the traditional elites, activists and core users are still becoming the main influencers of the social movement (Poell \& Dijck, 2017). The social media mapping in the COVID-19 hashtag mapping also found, if the social movement participants, in the some conversation clusters, do not show their potential to dominated in order to becoming the central of the movement, the central of the movement leaving to be role of the traditional individual organizations or actors which related to the their offline activities.

The social mediators in COVID-19 hashtag have a different behaviour. Core users which contains of 10 most active users in the movement, are trying to engage with and to expand their influence in the public (Smith et al., 2014), they showed a higher reciprocity than the elite mediators, who communicated in a more traditional one-way, or one-to-many, communication style even though they did it with their social media accounts.

The third findings, can be explained as the role of journalists and media. Journalists and media behave just like a private person, using humor and with the personal message between the journalist and media users to the private person. The role of media as an information gathering agent is changed as the network development agent. Supporting the argument above, the cross social structural movement makes the burden between mainstream media and ordinary people blurry. On the other hand, the role of activists and celebrities is creating calls to action. The information which comes from the journalist and media is retweeted by these clusters, creating a lot of the call for action movement. The account of @ Ekagustiwana for example, created a donation for the COVID-19 via Kitabisa for supporting the survivors of COVID-19 and their family by using information which was tweeted by the journalist and media previously.

The last findings, based on the social media mapping, are that there is an intense conversation cluster which contains all of the 
actors or protesters, which are against two opposite actors, which are the Government related accounts and International organization who have authority to do preventive and repressive actions in order to fight against COVID-19. Identified if there were two dominated users which role as the: "hubs" and "bridges" (Smith et al., 2014).

In this research, "Hubs" can be explained as the vertices which have a high amount of interactions with other other vertices, the vertices representing the users in a conversation network; in other words, a high in-degree value. For example, if a tweet by a conversation starter of an influencer has been re-tweeted/ commented by another user many times, the will hubs spread the tweet massively in their network. "Bridges" can be explained as the vertices which have a high value of the high betweenness centrality. Bridge users have capability to spread information across the subgroup boundaries and have the capability of passing information from one group to another. Those successful conversation networks in the diffused frames need both "hubs" and "bridges." To create a massive social movement. Even, the "bridges" users have not so many connections, they have big role that could diffuse message form the conversation starter and influencers, which dramatically increasing the conversation clusters to creating a social movement against the Government related accounts and International Organization who has authorities to do some actions against COVID-19 Outbreaks.

The impact of the movement can be analyzed directly by using the Timeline analysis. The digital social movement on Twitter using COVID-19 hashtags, creating a big impact on the COVID-19 Policy directions (WHO, 2019). The Influencer which contains the world's most influential person makes Government Related accounts and International Organization have the better policy, which comes from the people from various backgrounds worldwide. The timeline of policy can be shown in the figure 4 .

This research has several limitations. First of all, the people who posting and interacting on

Figure. 4.

COVID 19 related Policy as Results of the \#COVID19 Hashtag Waorldwide

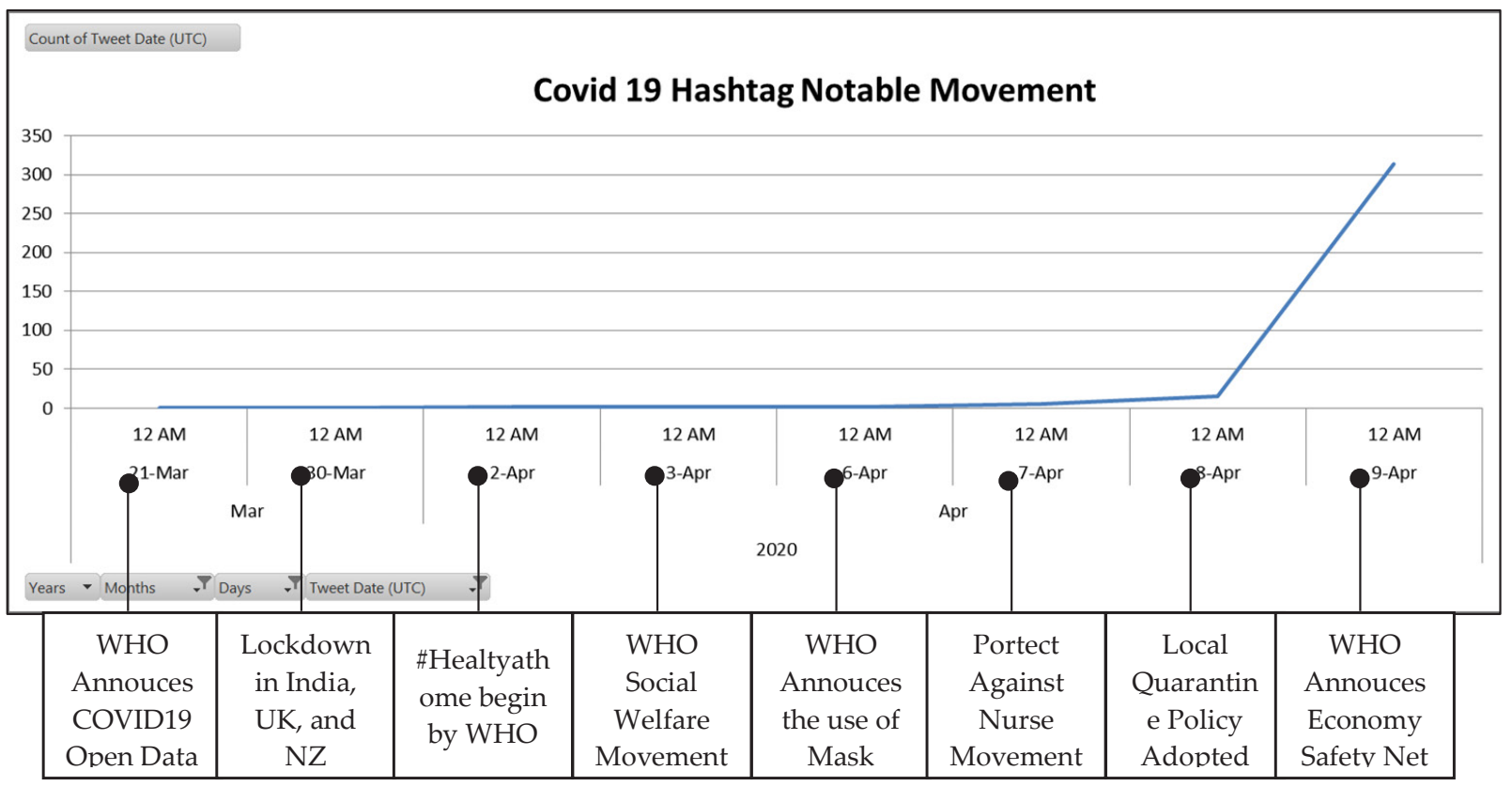

Source: World Health Organization, 2020 
the social media platform, Twitter, mostly comes from the special group, especially they are who interest to talk about COVID-19 in the Twitter, which means this research not represent all of the social structure in the society.

Moreover, the social movement on the internet itself cannot be analyzed by the Twitter social media platform alone. A deep survey must be conducted to understand COVID-19 social movement phenomenon, because the users who using social media to express their argument cannot consider as representation of a population, the internet penetration percentage, access to social media, and undocumented movement may occurs in the society (Derek \& Jürgen, 2014). Because of that, it's maybe biased and difficult to understand the real social movement which happens in a population.

However, this characteristic may be helpful if the research is focused on a group that is particularly active on a social media platform, and there is the potential to obtain data on groups who do not tend to respond to other research methods. Platforms can host numerous automated 'bots', and professionally managed accounts which pose as genuine human users. Large studies should therefore attempt to filter out results from such anomalous sources during analysis.

The potential which this research has can be valuable for the deeper and more accurate understanding about how the digital social movement is conducted and to figure out how the new social movements work in the further research.

\section{Conclusion}

The research findings, the digital social movement pattern, showed the difference if we compare it to the traditional social movement. The social movement in the digital era is characterized by the no boundaries movement and cross social structure, different from the traditional social movement which mostly conducted in the same social structure actors, those conditions before creating a borderless public sphere.

The findings support Rob Kitchin (2014) arguments, explaining if big data is successfully reframing Social Sciences and Humanities research, as the fourth wave of research revolution. Argued if the big data opens the exploratory research opportunities, which challenges the social sciences to adapt to the fast-changing of data-driven research with the dynamic environment which cannot be analyzed with the previous methodology. Also, the research finding emphasizes the Rob Kitchin arguments if the borderless public sphere can be utilized for the economy and political interest, and creating a virtual perspective among the society. Also, the virtual perspective can be removed the political boundaries between conversation network which happening in the digital public sphere (Wolfsfeld et al., 2013)

Interestingly, as explained before, in the theory of social movement which concluded as 4 (four) main steps, which are: "emergence," "coalescence," "bureaucratization," and "decline", the borderless social movement itself is still linear with the existing theory of social movement.

The social movement which happened in the online platform, can be concluded as 4 (four) main steps. In the first stage, the emergence period, movement actors who contain the media and ordinary people related accounts, become agitators and try to raise public awareness. Then in the second stage, which is called coalescence, celebrities, activists and ordinary person actors organized a related conversation cluster, resulting in the emerging leadership, and attracting large numbers of people who have various social backgrounds to join the movement, and massive waves of protest occurred on the internet. Then, the third stage, bureaucratization, the movement pushing the government related accounts. In the fourth stage, the social movements 
declined, because they had already reached the main goal (better policy to fight COVID-19 pandemic).

The pattern itself shown if the conversation clusters is contains all of the related actors from many of profiles background which contains from the with their own role, from the journalists, Private Person, Celebrity, Activist, Politician, Social Bot, NGO, International Organization, and Company who interact borderless, with the same goals. Known if the Activist, Journalist and Ordinary people identified to form a digital social movement against the government related accounts and International Organisation pushing for better policy in order to tackle COVID-19 Pandemic.

Furthermore, the research results emphasize the Kitchin argument in his book titled The data revolution: Big data, open data, data infrastructures $\mathcal{E}$ their consequences (2014), which said big data is the biggest transformation tools, to understand people's conversation, and transfers the power to the people. The results show if the social and political discourse is started mostly by the ordinary people, and creating a massive digital movement on the internet, resulted in the policy change.

\section{References}

Adalat, M., \& Niazi, M.A. (2017). Evaluating Roles of Central Users in Online Communication Networks: A Case Study of \#PanamaLeaks. http://arxiv.org/abs/1711.06845

Barbier, G., Feng, Z., Gundecha, P., \& Liu, H. (2013). Provenance Data in Social Media. Synthesis Lectures on Data Mining and Knowledge Discovery, 4(1), 1-84. https://doi.org/10.2200/ S00496ED1V01Y201304DMK007

Bernard, A. (2019). Theory of the Hashtag, Cambridge: Polity Press. Polity Press.

Binder, T. (2020, May 3). \#Covid 19 - Twitter evolution.

Bode, L., Hanna, A., Yang, J., \& Shah, D. v. (2015). Candidate Networks, Citizen Clusters, and Political Expression: Strategic Hashtag Use in the 2010 Midterms. Annals of the American Academy of Political and Social Science, 659(1), 149-165. https://doi. org/10.1177/0002716214563923

Borgatti, S., Everett, M., \& Freeman, L. (1992). UCINET IV : Network Analysis Software. Connections Journal, 15(1), 12-15.

Brunker, F., Wischnewski, M., Mirbabaie, M., \& Meinert, J. (2020). Hawaii International Conference on System Sciences 2020. (Vol. 53).

Derek, R., \& Jürgen, P. (2014). Social media for large studies of behavior. Science, 346(6213), 1063-1064. https://doi. org/10.1126/science.346.6213.1063

Dewantara, R. W., \& Widhyharto, D. S. (2016). Aktivisme dan Kesukarelawanan dalam Media Sosial Komunitas Kaum Muda Yogyakarta. Jurnal Ilmu Sosial Dan Ilmu Politik, 19(1), 40. https://doi.org/10.22146/ jsp.10855

Flesher Fominaya, C. (2010). Collective Identity in Social Movements: Central Concepts and Debates. Sociology Compass, 4(6), 393-404. https://doi.org/https://doi. org/10.1111/j.1751-9020.2010.00287.x

Isa, D., \& Himelboim, I. (2018). A Social Networks Approach to Online Social Movement: Social Mediators and Mediated Content in \#FreeAJStaff Twitter Network. Social Media and Society, 4(1). https://doi.org/10.1177/2056305118760807

Larson, J. M., Nagler, J., Ronen, J., \& Tucker, J. A. (2019). Social Networks and Protest Participation: Evidence from 130 Million Twitter Users. Source: American Journal of Political Science, 63(3), 690-705. https://doi. org/10.7910/DVN/RLLLIV

Mattoni, A., \& Treré, E. (2014). Media Practices, Mediation Processes, and Mediatization in the Study of Social Movements. Communication Theory, 24(3), 252-271. https://doi.org/https://doi.org/10.1111/ comt.12038 
Navarria, G. (2019). The Networked Citizen. Springer Singapore. https://doi. org/10.1007/978-981-13-3293-7

Papacharissi, Z., \& de Fatima Oliveira, M. (2012). Affective News and Networked Publics: The Rhythms of News Storytelling on \#Egypt. Journal of Communication, 62(2), 266-282. https://doi.org/10.1111/j.14602466.2012.01630.x

Park, S., Lee, J., Ryu, S., \& Hahn, K. S. (2015). The Network of Celebrity Politics: Political Implications of Celebrity Following on Twitter. Annals of the American Academy of Political and Social Science, 659(1), 246-258. https://doi.org/10.1177/0002716215569226

Petrič, G. (2006). Conceptualizing and Measuring the Social Uses of the Internet: The Case of Personal Web Sites. The Information Society, 22(5), 291-301. https:// doi.org/10.1080/01972240600904159

Poell, T., \& Dijck, J. van. (2017). Social media and new protest movements. https://www. researchgate.net/publication/321781377

Polletta, F., \& Jasper, J. M. (2001). Collective Identity and Social Movements. Annual Review of Sociology, 27(1), 283-305. https:// doi.org/10.1146/annurev.soc.27.1.283

Pond, P., \& Lewis, J. (2019). Riots and Twitter: connective politics, social media and framing discourses in the digital public sphere. Information, Communication $\mathcal{E}$ Society, 22(2), 213-231. https://doi.org/10. 1080/1369118X.2017.1366539
Porta, D. della, \& Diani, M. (2020). Social Movements: An Introduction, 3rd Edition (Vol. 3). Wiley Blackwell.

Sierra-Caballero, F. (2018). Cyberactivism and social movements. The Oppositional Public Space in contemporary technopolitics. https:// doi.org/10.4185/RLCS-2018-1292en

Smith, M. A., Rainie, L., Shneiderman, B., \& Himelboim, I. (2014, February 20). Mapping Twitter Topic Networks: From Polarized Crowds to Community Clusters. Pew Research Center. https://www. pewresearch.org/internet/2014/02/20/ mapping-twitter-topic-networks-frompolarized-crowds-to-communityclusters/

Welser, H. T., Gleave, E., Fisher, D., \& Smith, M. (2007). Visualizing the Signatures of Social Roles in Online Discussion Groups. In Journal of Social Structure (Vol. 8, Issue 2).

Wolfsfeld, G., Segev, E., \& Sheafer, T. (2013). Social Media and the Arab Spring: Politics Comes First. International Journal of Press/Politics, 18(2), 115-137. https://doi. org/10.1177/1940161212471716

World Health Organization. (2020, May 3). Timeline: WHO's COVID-19 response. WHO COVID-19 Updates.

Yates, L. (2015). Everyday politics, social practices and movement networks: daily life in Barcelona's social centres. The British Journal of Sociology, 66(2), 236-258. https:// doi.org/https://doi.org/10.1111/14684446.12101 